\title{
Water and Sanitary Conditions of a Typical Faculty of Public Health Building in a Nigerian University
}

\author{
Adejumo Mumuni", Ana Godson Rowland, Oloruntoba Elizabeth Omoladun, \\ Morakinyo Oyewale Mayowa, Hammed Taiwo Babatunde \\ Department of Environmental Health Sciences, Faculty of Public Health, College of Medicine, University of Ibadan, Ibadan, Nigeria
}

\section{Email address:}

adejumo_mumuni@yahoo.com (M. Adejumo), agree2000@yahoo.com (G. R. Ana), li_zzyy@yahoo.com (E. O. Oloruntoba), wahlemirax@gmail.com (O. M. Morakinyo),hammetab2003@yahoo.co.uk (T. B. Hammed)

${ }^{*}$ Corresponding author

\section{To cite this article:}

Adejumo Mumuni, Ana Godson Rowland, Oloruntoba Elizabeth Omoladun, Morakinyo Oyewale Mayowa, Hammed Taiwo Babatunde. Water and Sanitary Conditions of a Typical Faculty of Public Health Building in a Nigerian University. Science Journal of Public Health. Vol. 5, No. 2, 2017, pp. 103-109. doi: 10.11648/j.sjph.20170502.17

Received: January 6, 2017; Accepted: January 18, 2017; Published: February 17, 2017

\begin{abstract}
This study investigated water and sanitary conditions of a typical faculty of Public Health building, University of Ibadan, Nigeria. A cross-sectional study was conducted and 108 consented students and staff members were interviewed using a semi-structured questionnaire. Fifteen (15) toilet facilities with 45 rooms were also observed using an observational checklist. Respondents' age was $28.9 \pm 5.5$ years, $63.0 \%$ were female, $92.6 \%$ were students and all participants had completed tertiary education. The main source of water supply into the building was piped water $(85.2 \%)$ and $77.9 \%$ used it for flushing toilet. Only $22.2 \%$ reported that the water source is readily accessible all the time while $63.0 \%$ stated that the quantity of water available got depleted during the afternoon time. On-site observations revealed that $8(53.4 \%)$ of the toilet facilities had inadequate water supply. Majority (81.5\%) reported water closet as the main type of sanitary convenience in the building while the major shortcomings of the toilets mentioned were non-accessibility $(88.9 \%)$ and shortage of water supply (77.8\%). All $(100 \%)$ of the toilet rooms observed had no severe odour while $2(4.4 \%)$ of the toilet rooms had appreciable quantities of vectors breeding. About fifty-nine percent had good attitude towards the sanitary conveniences within the building and significantly, $75.0 \%$ of female respondents had good attitude compared to $25.0 \%$ of their male counterpart ( $<<0.05$ ). Twelve $(11.1 \%)$ respondents said they practiced handwashing with water and soap and none $(0.0 \%)$ reported presence of signs that encourage good hygiene practices in the toilet. Wash hand basins was observed to be present and functional within all the 15 $(100 \%)$ toilet facilities, water was present in $10(66.7 \%)$ of the facilities while soap was absent in all the $15(100 \%)$ facilities observed. Constant water supply should be sustained, handwashing materials and signs that encourage good hygiene practices should be provided within the toilets.
\end{abstract}

Keywords: Water Quality, Sanitary Condition, Sanitary Conveniences, Hand Washing Practice

\section{Introduction}

Appropriate and adequate sanitation, good hygiene and safe water supply are fundamental to good health, social, economic and educational development. Little wonder why the Prime Minister of India in 2008 quoted Mahatma Gandhi who said in 1923, "sanitation is more important than independence" [1]. Improvements in one or more of these three components of public health can substantially reduce the rates of morbidity and the severity of various diseases and improve the quality of life of huge numbers of people [2]. Sanitation could be defined as the safe disposal of human excreta [3]. This does not only imply that people must excrete hygienically but also that their excreta must be contained or treated to avoid adversely affecting their health or that of other people.

Lack of adequate sanitation leads to disease and about a half of the urban population of Africa, Asia, and Latin America have a disease associated with poor sanitation, hygiene, and water [4] Without doubt, faeces are the most dangerous to human health out of the excreta. One gram of fresh faeces 
from an infected person can contain around $10^{6}$ viral pathogens, $10^{6}-10^{8}$ bacterial pathogens, $10^{4}$ protozoan cysts or oocysts, and 10-10 ${ }^{4}$ helminth eggs [5]. These could cause water-borne diseases including diarrhea, typhoid etc. Diarrhea and water-borne diseases are leading causes of morbidity and mortality in developing countries including Nigeria [6]. Approximately $88 \%$ of diarrhea diseases are attributed to unsafe water supply, inadequate sanitation and hygiene [7].

Whilst water and sanitation infrastructure provide the physical conditions for hygiene, they cannot alone prevent the transmission of these diseases in domestic or institutional settings. Sanitation has to be used in a hygienic and acceptable manner by all to prevent excreta reaching the environment and to prevent excreta contaminating water supplies. Hand washing with soap can both help to prevent diarrhea causing organisms reaching the environment and prevent the subsequent contamination of food and water. Also, much of the water available for communities is unsafe $[8,9,10]$ in Nigeria and may contribute to water-borne or water- related infections. Water which is required for various purposes at various setting such as household and institutions poses serious health effects when it is not available and accessible or the supply is inadequate. Even when facilities are put in place, poor operation, and maintenance practices have in many instances largely contributed to a decreased use and even an early failure of water supply and sanitation facilities [11].

Moreover, improved sanitation ensures both social and economic benefits which include the desire for privacy and to avoid embarrassment, wanting to be modern, the desire for convenience and to avoid the discomforts or hazards associated with the bush (e.g., snakes, pests, rain), and wanting social acceptance or status [12, 13]. Furthermore, it is very necessary to make provision for separate sanitation facilities for boys and girls especially in institutional settings including schools. Provision of school sanitation facilities means that school girls are less likely to miss school by staying at home during menstruation [14]. Although studies have documented sanitary conditions and water supply at the household levels in Nigeria, adequacy and appropriateness of sanitary facilities and water supply in higher institutional settings had not been adequately assessed. Regrettably, numerous sanitary facility users (staff members and students) often exceed the number of available and accessible facilities in various higher institutions of learning in Nigeria. Thus, this study was aimed at assessing water and sanitary conditions of a typical faculty of Public Health building at the University of Ibadan, Nigeria.

\section{Methods}

\subsection{Study Design and Study Location}

This study adopted an institutional-based, cross-sectional design which used survey method with semi-structured interview administered questionnaire and onsite observational checklist. The interview was carried out among consented faculty members and postgraduate students in the faculty while the observation was carried out on the sanitation facilities within the faculty building (Figure 1).

The Faculty of Public Health (Oladele Ajose) building, University College Hospital, University of Ibadan was purposively selected. This is due to the emergence of new departments, recruitment of more staff members and an increase in the number of student's enrollment per academic session. The building complex, formerly known as Department of Preventive and Social Medicine was one of the four foundation clinical departments of the Faculty of Medicine established for the training of medical doctors in 1948. It was transformed to the present Faculty of Public Health. The Faculty of Public Health building was named after Professor Oladele Ajose who was the Head of Department of Preventive and Social Medicine (1948-1962) cum the Director of the Institute of Public Health. The institute was one of the pioneer faculties of the University College Hospital that was established in 1957. The entire complex which was commissioned over two decades ago is divided into the new and old complexes. It is located at about $200 \mathrm{~m}$ from the main gate of the University College Hospital. The new building complex is made up of 3 floors with more than 50 offices asides classrooms, laboratories, library and computer rooms, and is currently being used by 5 Departments.

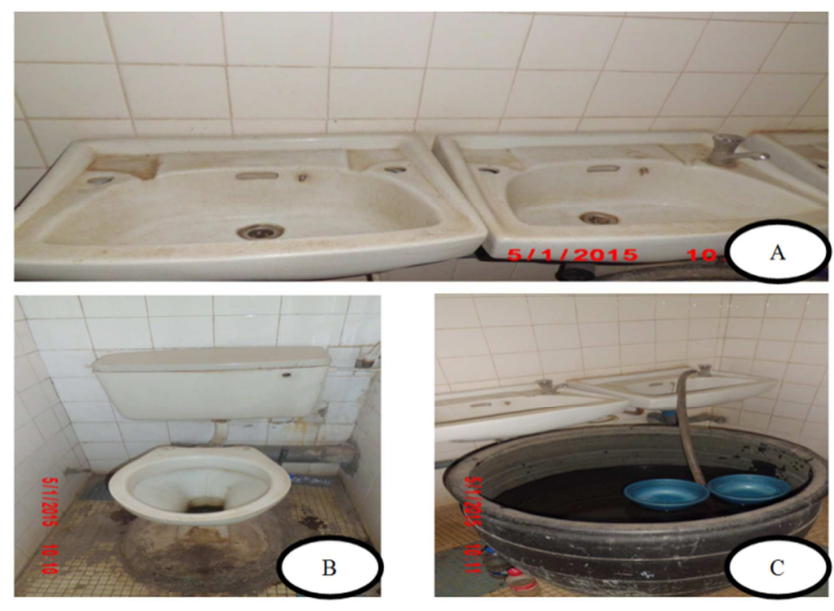

Figure 1. Water supply, sanitary and handwashing facility at Oladele Ajose Building: A-Handwashing facilities; B-Sanitation facility and C-Water supply system.

\subsection{Study Population and Sampling Techniques}

This study was carried out among sanitary conveniences users including students and staff members in the Oladele Ajose building. One hundred and eight (108) consented staff members and students participated in the study. In addition, 15 toilets facilities with 45 toilet rooms were observed using an observational checklist. Purposive sampling technique was used to select the consented participants. Consenting students and staff members within the building selected were interviewed using a validated self administered questionnaire.

\subsection{Data Collection Procedure}

During data collection, the research assistants explained 
the study objectives to the participants to ensure that they understood all aspects of the study. Also, consent forms after they had been completed and signed, were obtained from the students and staff members who participated in the study. Participants that declined to participate were excluded from the study. A set of pretested, semi-structured questionnaire was developed to elicit information such as demographic characteristics, water supply, sanitary convenience, and attitude towards the use of sanitary convenience, hand washing practice and health condition from the participants. In addition, water and sanitary conditions were observed using a validated observational checklist. The instrument were distributed to the participants by trained research assistants (male and female) who are postgraduate student and were acquainted with questionnaire research. They were trained in how to use the instrument and how they should introduce themselves and the research objectives modestly to the participants during the data collection. Completed questionnaire were collected from the participants and prepared for data management.

\subsection{Data Analysis}

Data generated from the field were edited daily. Then they were coded and entered into the computer for analyses using Epi-Info 6.04 statistical software packaged. Data were presented as mean standard deviation for continuous variables and percentages for categorical variables. Chisquare statistic was used to determine the associations between demographic characteristics and respondent's attitude towards the use of sanitary convenience. Statistical significance was defined at $\mathrm{p}<0.05$.

\section{Results}

\subsection{Socio-demographic Profile of the Respondents}

Table 1 presents the demographic characteristics of the participants. The mean age which ranged from $22-50$ years was $28.9 \pm 5.5$ years. There were $(63.0 \%)$ female and (37.0\%) male. Most (92.6\%) were Christians and 7.4\% practice Islam. Majority (77.8\%) were single, $22.2 \%$ were married, all (100.0\%) had completed tertiary education while most $92.6 \%$ were students.

Table 1. Socio-demographic characteristics.

\begin{tabular}{lll}
\hline Socio-demographic characteristics & Number $\mathbf{N = 1 0 8}$ & $\mathbf{\%}$ \\
\hline Age (years)* & & \\
$\leq 30$ & 80 & 74.1 \\
$31-40$ & 24 & 22.1 \\
41 and above & 4 & 3.7 \\
Gender & & \\
Male & 40 & 37.0 \\
Female & 68 & 63.0 \\
Religion & & \\
Christianity & 100 & 92.6 \\
Islam & 8 & 7.4 \\
Marital status & & \\
Single & 84 & 77.8 \\
\hline
\end{tabular}

\begin{tabular}{lll}
\hline Socio-demographic characteristics & Number $\mathbf{N = 1 0 8}$ & $\mathbf{\%}$ \\
\hline Married & 24 & 22.2 \\
Educational Level & & \\
No formal education & 0 & 0.0 \\
Primary school education & 0 & 0.0 \\
Secondary school education & 0 & 0.0 \\
Tertiary education & 108 & 100.0 \\
Occupation & & \\
Teaching & 4 & 3.7 \\
Non-teaching & 4 & 3.7 \\
Students & 100 & 92.6 \\
\hline
\end{tabular}

$*=28.9 \pm 5.5$ years, Minimum age $=22$ years, Maximum age $=50$ years

\subsection{Water Supply}

The major sources of water supply to Ajose building mentioned by the respondents were piped water $(85.2 \%)$, Bottled water $(48.1 \%)$ and sachet-pure water $(44.4 \%)$ as depicted in Figure 2. Majority (81.5\%) used the water for hand washing, $77.89 \%$ used it for flushing toilet while $29.6 \%$ used it for anal cleansing. Only $22.2 \%$ said the water source is readily accessible all the time, $29.6 \%$ stated that water quantity is adequate while $63.0 \%$ stated that quantity of water get depleted during afternoon time (12-4.30pm) as presented in Table 2. On-site observation revealed that 8 $(53.4 \%)$ of the toilet facilities had inadequate water supply, 9 $(60 \%)$ each had inadequate quantity and quality of water supply respectively while $6(40.0 \%)$ had adequate drainage system as presented in Table 3 .

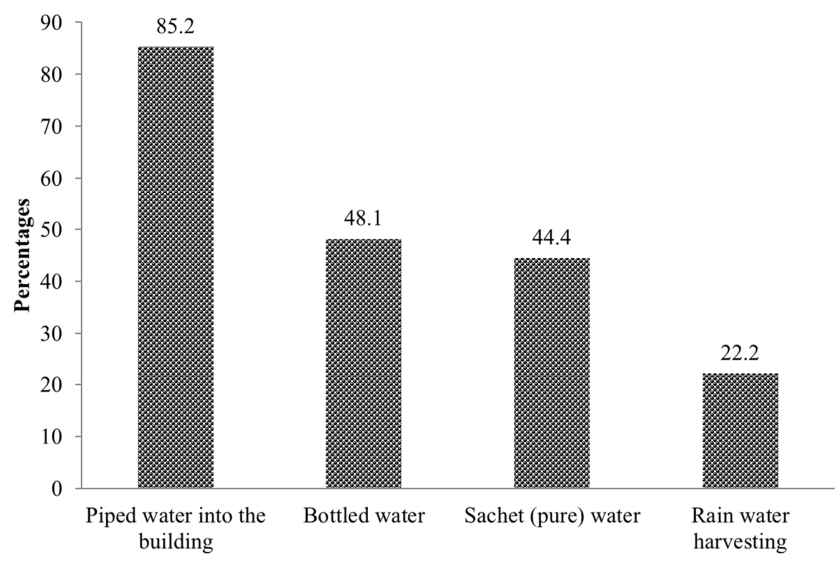

Figure 2. Sources of water supply in Ajose Building.

Table 2. Uses, accessibility and adequacy of water source in Ajose Building.

\begin{tabular}{ll}
\hline Uses, accessibility and adequacy of water source & Number (\%) \\
\hline Uses of water & \\
Flushing toilet & $84(77.8)$ \\
Hand washing & $88(81.5)$ \\
Washing & $32(29.6)$ \\
Water sources readily accessible all the time & $24(22.2)$ \\
Water quantity were adequate & $32(29.6)$ \\
Time of the day quantity of water get depleted & \\
Morning (8-11.30 am) & $4(3.7)$ \\
Afternoon (12-4.30pm) & $68(63.0)$ \\
All the time & $28(25.9)$ \\
Don't know & $8(7.4)$ \\
\hline
\end{tabular}


Table 3. Observed water availability in toilet facilities in Ajose Building.

\begin{tabular}{llll}
\hline Water availability & $\begin{array}{l}\text { Adequate } \\
(\mathbf{\%})\end{array}$ & $\begin{array}{l}\text { Fairly } \\
\text { adequate (\%) }\end{array}$ & $\begin{array}{l}\text { Inadequate } \\
(\%)\end{array}$ \\
\hline Water supply & $5(33.3)$ & $2(13.3)$ & $8(53.4)$ \\
Quantity of water supply & $4(26.7)$ & $2(13.3)$ & $9(60)$ \\
Quality of water supply & $4(26.7)$ & $2(13.3)$ & $9(60)$ \\
Water storage container & $4(26.7)$ & $2(13.3)$ & $9(60)$ \\
Good drainage system & $6(40.0)$ & $4(26.7)$ & $5(33.3)$ \\
\hline
\end{tabular}

\subsection{Sanitary Convenience}

Majority (81.5\%) of the respondents reported water closet as the main type of sanitary convenience in the building, only $7.4 \%$ said the sanitary convinineces were suitable for intended population while $74.4 \%$ revealed that separate toilet for male and female were available as shown in Table 4. Separate toilets for students and staffs, and separate toilets for persons with disability were reported to be un-available $(0.0 \%)$ while $0.9 \%$ said the toilets were adequate for intended population. Most $(92.6 \%)$ stated that water is sometimes available in the toilet and (11.1\%) said water for cleaning pupose was adequate. Any type of urinal in the toilet was reported to be unvailable $(0.0 \%)$ and the major shortcomings of the toilets within the building were non-accessibility (88.9), shortage of water supply to the toilet (77.8\%) and bad odour $(74.2 \%)$. It was observed that odour in all the toilet rooms was not intense, no severe injuries were observed in all the toilet rooms while $43(95.6 \%)$ of the toilet rooms had no serious vector breeding within the toilet as seen in Table 5 .

Table 4. Sanitary conveniences in Ajose Building.

\begin{tabular}{ll}
\hline Sanitary convenience & Number (\%) \\
\hline Types of toilet in the building & $0(0.0)$ \\
Pit & $0(0.0)$ \\
Ventilated Improved Pit & $88(81.5)$ \\
Water Closet & $8(7.4)$ \\
Suitability of sanitary convenience for intended & $76(70.4)$ \\
population & $0(0.0)$ \\
Availability of separate toilet for male and female & $0(0.0)$ \\
Availability of separate toilet for students and staff & $1(0.9)$ \\
Availability of separate toilet for person with disability & \\
Adequacy of sanitary convenience for intended & \\
population & $8(7.4)$ \\
Frequency of water availability & $100(92.6)$ \\
Always & $0(0.0)$ \\
Sometimes & $12(11.1)$ \\
Not at all & $0(0.0)$ \\
Adequacy of water for cleaning in the toilet & $86(88.9)$ \\
Availability of any type of urinal in the toilet & $84(77.8)$ \\
Shortcomings of toilet within the building & $36(33.3)$ \\
Bad odour & $12(11.1)$ \\
Attracts flies & $48(44.4)$ \\
Not accessible & $12(11.1)$ \\
Shortage of water supply & $96.1)$ \\
Not separated by staff/student & \\
\hline & \\
\hline
\end{tabular}

Table 5. Observed environmental problems within toilet rooms in Ajose Building.

\begin{tabular}{|c|c|c|c|c|}
\hline $\begin{array}{l}\text { Environmental } \\
\text { problems }\end{array}$ & $\begin{array}{l}\text { Very severe } \\
\text { (\%) }\end{array}$ & $\begin{array}{l}\text { Severe } \\
(\%)\end{array}$ & $\begin{array}{l}\text { Less } \\
\text { severe (\%) }\end{array}$ & $\begin{array}{l}\text { Not severe } \\
(\%)\end{array}$ \\
\hline Injuries & $0(0.0)$ & $0(0.0)$ & $0(0.0)$ & $45(100)$ \\
\hline $\begin{array}{l}\text { Vectors breeding } \\
\text { within the toilet }\end{array}$ & $2(4.4)$ & $0(0.0)$ & $0(0.0)$ & $43(95.6)$ \\
\hline Littering of the toilet & $2(4.4)$ & $0(0.0)$ & $0(0.0)$ & $43(95.6)$ \\
\hline $\begin{array}{l}\text { Evidence of pipe } \\
\text { leakages within the } \\
\text { toilet }\end{array}$ & $0(0.0)$ & $0(0.0)$ & $0(0.0)$ & $45(100)$ \\
\hline
\end{tabular}

\subsection{Attitude Towards the Use of Sanitary Convenience}

Slightly more than half $5.8 \%$ agreed that the sanitary conveniences are not evenly distributed within the building, $55.5 \%$ disagreed that water supply is satisfactory and best done by running tap while $92.6 \%$ disagreed that hand washing facility including water, soap or detergent are always available within the sanitary convenience. Majority $74.0 \%$ agreed that there is possibility of contacting infections from the toilets because most of them are not cleaned regularly, $51.8 \%$ disagreed that the cleaners are not competent to clean the facilities whereas $74.0 \%$ agreed that involvement of faculty members in monitoring and supervision of the cleaning process will guarantee a well sanitised facility.

Figure 3 illustrates the attitudinal category of the respondents with $59.3 \%$ showing good attitude towards the sanitary conveniences within the building. However, $75.0 \%$ of respondents who were 30 years and below had good attitude towards sanitary convenience in the building compared to $72.2 \%$ who had poor practice. The association was not significant $(\mathrm{p}>0.05)$. A significantly high proportion $75.0 \%$ of female respondents had good attitude compared to $25.0 \%$ of their male counterpart $(p<0.05)$. Majority of single respondents $68.8 \%$ had good attitude compared to $31.2 \%$ of those who are married. A significant association existed between respondents' marital status and attitude category (See Table 6 for detail).

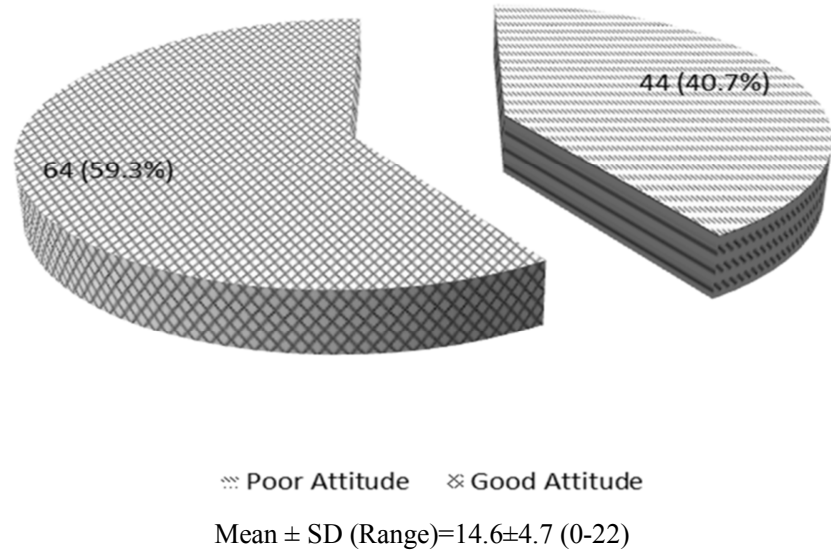

Figure 3. Attitudinal category of the respondents. 
Table 6. Comparison of socio-demographic characteristics and respondents attitude towards the use of sanitary convenience.

\begin{tabular}{|c|c|c|c|}
\hline \multirow{2}{*}{$\begin{array}{l}\text { Socio-demographic } \\
\text { characteristics }\end{array}$} & \multicolumn{2}{|c|}{$\begin{array}{l}\text { Attitude towards the use } \\
\text { of sanitary convenience }\end{array}$} & \multirow[t]{2}{*}{$\chi^{2}$ (p Value) } \\
\hline & Poor (\%) & Good (\%) & \\
\hline \multicolumn{4}{|l|}{ Age (years) } \\
\hline$\leq 30$ years & $32(72.7)$ & $48(75.0)$ & \multirow{3}{*}{$3.620(0.16)$} \\
\hline $31-40$ years & $12(27.3)$ & $12(18.8)$ & \\
\hline 41 years and above & $0(0.0)$ & $4(6.2)$ & \\
\hline \multicolumn{4}{|l|}{ Sex } \\
\hline Male & $24(54.5)$ & $16(25.0)$ & \multirow[t]{2}{*}{$9.760(0.02)$} \\
\hline Female & $20(45.5)$ & $48(75.0)$ & \\
\hline \multicolumn{4}{|l|}{ Marital status } \\
\hline Single & $40(90.9)$ & $44(68.8)$ & \multirow[t]{2}{*}{$7.407(0.06)$} \\
\hline Married & $4(9.1)$ & $20(31.2)$ & \\
\hline \multicolumn{4}{|l|}{ Occupation } \\
\hline Teaching & $0(0.0)$ & $4(6.2)$ & \multirow{3}{*}{$8.591(0.01)$} \\
\hline Non-Teaching & $4(9.1)$ & $0(0.0)$ & \\
\hline Students & $40(90.9)$ & $60(93.8)$ & \\
\hline
\end{tabular}

\subsection{Hand Washing Practices and Health Conditions}

Majority $81.5 \%$ revealed that there was evidence of hand washing facilities within the building, 51.9\% said water was available while none $(0.0 \%)$ reported availability of soap/ash in the handwashing facility as shown in Table 7. Large proportion, $85.2 \%$ stated that they regularly washed their hands after using the toilet, 80 $(74.1 \%)$ did handwashing with water only while 12 $(11.1 \%)$ did so with water with soap/detergent. None $(0.0 \%)$ each reported availability of hand drying material and presence of signs that encourage good hygiene practices in the toilet. From Table 8, wash hand basin were present and functional within all the $15(100 \%)$ toilet facilities observed, water was present in $10(66.7 \%)$ of the facilities while soap/ash was absent in all the $15(100 \%)$ facilities observed.

Most $92.6 \%$ perceived utilization of any unsanitary toilet as a health threat while the major threats expected from an unsanitary toilet were infections from microscopic organisms (92.6\%), exposure to diseases causing germs $(88.9 \%)$ and exposure to parasitic organisms that can cause ailment $(77.8 \%)$ as seen in Table 9. Some of the suggested ways to improve sanitary conditions of the building mentioned were constant water supply $(77.8 \%)$, provision of handwashing materials (44.4\%), make toilet accessible to all (33.3\%) and regular toilet sanitation $(25.9 \%)$.

Table 7. Hand washing practices in Ajose building.

\begin{tabular}{ll}
\hline Hand washing practices & Number (\%) \\
\hline Evidence of hand washing facility within the building & $88(81.5)$ \\
Availability of water in the handwashing facility & $56(51.9)$ \\
$\begin{array}{l}\text { Availability of soap/ash in the handwashing facility } \\
\text { Regular handwashing after using the toilet }\end{array}$ & $0(0.0)$ \\
$\begin{array}{l}\text { Materials for Hand washing } \\
\text { Water only }\end{array}$ & $92(85.2)$ \\
$\begin{array}{l}\text { Water with soap/ash } \\
\text { Availability of hand drying material in the toilet } \\
\text { Presence of signs that encourage good hygiene practices } \\
\text { in the toilet }\end{array}$ & $00(74.1)$ \\
\hline
\end{tabular}

Table 8. Observations about hand washing facilities in Ajose Building.

\begin{tabular}{llll}
\hline $\begin{array}{l}\text { Hand washing } \\
\text { facility }\end{array}$ & $\begin{array}{l}\text { Absent } \\
(\%)\end{array}$ & $\begin{array}{l}\text { Present and Non } \\
\text { functional (\%) }\end{array}$ & $\begin{array}{l}\text { Present and } \\
\text { functional (\%) }\end{array}$ \\
\hline $\begin{array}{l}\text { Wash hand basin } \\
\text { within the toilet }\end{array}$ & $0(0.0)$ & $0(0.0)$ & $15(100)$ \\
Water & $5(33.3)$ & $0(0.0)$ & $10(66.7)$ \\
Soap & $15(100)$ & $0(0.0)$ & $0(0.0)$ \\
Ash & $15(100)$ & $0(0.0)$ & $0(0.0)$ \\
\hline
\end{tabular}

Table 9. Perceived Health conditions within Ajose Building.

\begin{tabular}{ll}
\hline Health conditions & Number (\%) \\
\hline $\begin{array}{l}\text { Perceived health threat from utilization of any unsanitary } \\
\text { toilet }\end{array}$ & $100(92.6)$ \\
Threats expected from an unsanitary toilet & \\
Infections from microscopic organisms & $100(92.6)$ \\
The use is exposed to diseases causing germs & $96(88.9)$ \\
Parasitic organisms that can cause ailment & $84(77.8)$ \\
Suggestions to improve sanitary conditions of the building & \\
Constant water supply & $84(77.8)$ \\
Provision of handwashing materials & $48(44.4)$ \\
Provision of air fresheners to remove odour & $8(7.4)$ \\
Provision of better cleaning materials for the cleaners & $16(14.8)$ \\
Make toilet accessible to all & $36(33.3)$ \\
Differentiate for male and female & $8(7.4)$ \\
Constant supervision and monitoring of toilet and cleaner & $16(14.8)$ \\
Regular toilet sanitation & $28(25.9)$ \\
Put instruction for handwashing and others & $8(7.4)$ \\
Replace the toilet closet & $4(3.7)$ \\
\hline
\end{tabular}

\section{Discussion}

The current investigation assessed the water and sanitary conditions of Oladele Ajose building in the College of medicine, University of Ibadan. This study found that major sources of water supply to Ajose building were piped water, bottled water and sachet-pure water. Large proportion reported that the water source was not readily accessible all the time. Large percentage of the respondents stated that the quantity of water get depleted during the afternoon time (12$4.30 \mathrm{pm})$. This is an indication that the water supply to this building was inadequate both in terms of the quantity, accessibilty and quality. The findings could be a source of worry for the users since the level of personal hygiene required after using the toilet facility will be compromised because of inadequate water supply within the facility. This is in accordance with a [15] report which states that lack of safe water, sanitation and prevalence of poor hygiene behaviors is the major cause of death among students in developing countries, and that a contaminated environment and poor hygiene practices account for over $60 \%$ of the total burden of disease among students in these countries.

According to [16], hygiene behaviors include proper hand washing, regular bathing and laundering, safe disposal of waste, and proper use of toilets which will help in enhancing effective learning, attracting large student enrolment in schools and ensuring a reduced burden of diseases. These practices among both the students and the staff members within the complex will be hindered with inadequate water supply and hand washing facilities. Both the survey findings and results from onsite-observations were similar where 
more than half of the toilet facilities had inadequate water supply while about two-third had inadequate quantity and quality of water supply respectively. Although majority revealed that separate toilets for male and female were available, separate toilets for students and staff, and separate toilet for person with disability were reported to be unavailable. It was also discovered that most of the participants reported that the toilets were inadequate for intended population. This is similar to the findings of several studies $[17,18,19]$ where most of the sanitation facilities were not adequate in their respective study areas. Though, the norms vary considerably ranging from 1 toilet/urinal for 25 girls or boys in one country up to 1 toilet for more than 100 children in another country [20].

Regrettably, during a water and sanitation workshop that was conducted at Burkina Faso in 2000 it was reported that only 1 toilet was being used by 381 students and 1 urinal by 892 students [21]. Further, on-site observation revealed that any type of urinal was not available in all the toilets visited. These findings contradict the guideline of 1 toilet plus one urinal for 50 boys and 1 toilet for 25 girls set by the World Health Organization [22]. In additioin, large proportion stated that toilets within the building were non-accessible and sometimes there is shortage of water supply to the sanitation facilities within the building. The toilets within the building were observed to have minimal odour, injuries and vectors breeding problems. This contradicts the report of several studies where students could not use toilets because of some reasons including bad odour [23, 24, 25].

Large proportion reported that hand washing facility including water, soap or detergent are always not available within the sanitary convenience. Unavailability of these facilities could hinder appropriate handwashing practices of the users. Although the study was conducted in secondary school, [26] reported lack of soap as one of the barriers to hand washing in the schools since most of the schools have neither soap nor appropriate hand washing facilities. Majority stated that there is possibility of contacting infections from the toilets because most of the facilities were not cleaned regularly. Most of the participants revealed that involvement of faculty members in monitoring and supervision of the cleaning process will ensure a well sanitised facility. This is an indication that appropriate supervision of the sanitation facilities and cleaners will ensure proper cleaning and maintenance of the sanitation facilities within the building.

All the respondents reported absence of signs and educational materials that encourage good hygiene practices in the toilet. Without doubt, these educational materials will not only instruct, direct the users on healthy hygiene practices but also enhance proper practices in order to reduce or eliminate water and sanitation related diseases among the users. Although, wash hand basin were observed to be present and functional within all the toilet facilities, only 10 $(66.7 \%)$ had water while none of the toilet facilities had soap/ash for proper handwashing. Provision of either soap/detergent or ash within the sanitation facilities is very essential as healthy handwashing practices could not be achieved with neither soap/detergent nor ash. Participants suggested that constant water supply, provision of handwashing materials, making toilet accessible to all and regular toilet sanitation were esential to improve the teaching, learning and research within the complex.

\section{Conclusion}

The study found that major sources of water supply to Ajose building were piped water, bottled water and sachet water and they were mostly used for hand washing and flushing toilet. Though separate toilets for male and female were available but separate toilets for students and staffs, and for person with disability were unavailable. Sanitation facilities were not adequate for intended population. The study found that any type of urinal in the toilet was not available and toilets within the building were non-accessible and sometimes shortage of water supply to the sanitation facilities within the building do occur. Observation revealed thay toilets had less problems of odour, injuries and vectors breeding. Furthermore, hand washing facilities including water, soap or ash were always not available within the sanitary convenience. Although, wash hand basins were observed to be present and functional within all the toilet facilities, about two-third had water while none of the toilet facility had soap/ash for proper handwashing. Most of the participants agreed that involvement of faculty member in monitoring and supervision of the cleaning process will ensure a well sanitised facility. In addition, observation shows that no signs and educational materials that encourage good hygiene practices were available in the toilet. Arising from these therefore, constant water supply should be sustained, handwashing materials and educational signs that encourage good hygiene practices should be provided within the toilets.

\section{Acknowledgements}

The authors acknowledge the contributions and supportive role of Mr. Aniedi David and the entire class of 2012/2013 Masters of Public Health (Department of Environmental Health Sciences) Students, College of Medicine, University of Ibadan, Ibadan, Nigeria towards the successful completion of this study.

\section{References}

[1] Singh, M. Opening address to the third South Asian conference on sanitation, New Delhi, 18 November 2008. Available:

https://sanitationupdates.wordpress.com/category/regions/sout h-asia/page/71/ [Accessed 06 January 2017].

[2] Esrey, S. A., Potash, J. B., Roberts, L. and Shiff, C. Effects of improved water supply and sanitation on ascariasis, diarrhoea, dracunculiasis, hookworm infection, schistosomiasis, and trachoma. Bulletin of World Health Organization, 1991; 69: 609-621. 
[3] WHO/UNICEF. Progress on sanitation and drinking-water 2010 update. Geneva: World Health Organization, 2010; pp160 .

[4] WHO. Creating healthy cities in the 21 st century. In: Satterthwaite D, editor. The Earthscan reader on sustainable cities. London: Earthscan Publications, 1999; pp 137-172.

[5] Feachem, R. G., Bradley, D. J., Garelick, H. and Mara, D. D. Sanitation and disease. Health aspects of wastewater and excreta management. Chichester: John Wiley and Sons. 1983; $326 \mathrm{p}$.

[6] WHO/UNICEF. Joint Monitoring Programme for Water Supply and Sanitation, Global water supply and sanitation assessment, report, 2000. WHO, Geneva. 2000; Available: http://www.who.int/water_sanitation_health/monitoring/jmp2 000.pdf [accessed 06 January 2017].

[7] WHO. Water Sanitation and Hygiene links to Health, Facts and Figures, updated March 2004. WHO, Geneva. 2004; Available:

http://www.who.int/water_sanitation_health/en/factsfigures04. pdf [accessed 06 January 2017].

[8] Enabor, B., Sridhar, M. K. C., and Olaseha, I. O. Integrated water management by urban poor women: A Nigerian slum experience. Water Resources Development. 1998; 14 (4): 505512.

[9] Oloruntoba, E. O., Agbede, O. A. and Sridhar, M. K. C. Seasonal variation in physicochemical quality of household drinking water in Ibadan, Nigeria. ASSET- An International Journal. 2006; (Series B) 5 (1): 70-81.

[10] Oloruntoba, E. O. and Sridhar, M. K. C. Bacteriological quality of drinking water from source to household in Ibadan, Nigeria. African Journal of Medicine and Medical Sciences. 2007; 36: 169-175.

[11] DFID. Water: Knowledge and Research: Department of International Development. 2004; Issue 18: p12.

[12] Jenkins, M. W. and Curtis, V. Achieving the 'good life': Why some people want latrines in rural Benin. Soc Sci Med. 2005; 61: 2446-59.

[13] Jenkins, M. W. and Scott, B. Behavioral indicators of household decision-making and demand for sanitation and potential gains from social marketing in Ghana. Social Science Med. 2007; 64: 2427-42.

[14] Mahon, T. and Fernandes, M. Menstrual hygiene in South Asia: a neglected issue for WASH (water, sanitation and hygiene) programmes. Gend Dev. 2010; 18.1: 99-113.

[15] UNICEF and WHO. Diarrhea: Why children are still dying and what can be done Geneva. 2009; Available: whqlibdoc.who.int/publications/2009/9789241598415_eng.pd $f$ [accessed 06 January 2017].

[16] Water Supply and Sanitation Collaborative Council. Vision 21: A shared vision for hygiene and water supply and framework for action. Proceedings of the Second World Water Forum, The Hague - 22, March, Geneva, Switzerland. 2010.

[17] Siwolo, I. A. The Financial Challenges Facing the Management of Primary Schools after the Introduction of F. P. E: A case of Wetlands Division, Nairobi. Kenya; Unpublished Med Thesis. Nairobi: Kenyatta University. 2004.

[18] Asyago, B. An Investigation into the Challenges Facing the Free Primary Education Management: The Case of Machakos District. Kenya. Unpublished Med Thesis, Nairobi: Kenyatta University. 2005.

[19] Mugo, E. W. Strategies Adopted by Primary Schools Head teachers in Managing Free Primary Education in Embu District Kenya: Unpublished Med Thesis, Nairobi: Kenyatta University. 2006.

[20] Zomerplaag, J. and Mooijman, A. Child - friendly hygiene and sanitation facilities in schools: indispensable to effective hygiene education. Technical paper series No. 47. International water and sanitation centre, Delft and United Nations Children's Fund, New York. 2005.

[21] World Health Organization. WHO Guidelines on Hygiene Practices. WHO Press, Geneva 27, Switzerland. 2006

[22] World Health Organization. Water, Sanitation and Hygiene Standards for Schools in Low-Cost Settings. Geneva, Switzerland. 2009.

[23] Njuguna V., Karanja B., Thuranira M., Shordt K., Snel M., Cairncross S., Biran A., Schmidt W.-P. The Sustainability and Impact of School Sanitation, Water and Hygiene Education in Kenya. UNICEF and IRC International Water and Sanitation Centre; New York, NY, USA and Delft, The Netherlands. 2008.

[24] Lundblad B., Hellstrom A. L. Perceptions of school toilets as a cause for irregular toilet habits among schoolchildren aged 6 to 16 years. Journal of School Health. 2005; 75: 125-128.

[25] Vernon S., Lundblad B., Hellstrom A. L. Children's experiences of school toilets present a risk to their physical and psychological health. Child Care, Health Development. 2003; 29: 47-53.

[26] Bolt, E., Shordt, K. and Krukkert, I. School sanitation and hygiene education results from the assessment of a 6-country pilot project delft. International Water and Sanitation Centre, Netherlands. 2006. 